\title{
EFFECT OF SINGLE-NUCLEOTIDE POLYMORPHISMS ON SPECIFIC REPRODUCTION PARAMETERS IN HUNGARIAN LARGE WHITE SOWS
}

\author{
Eszter Erika BALOGH ${ }^{1}$, György GÁBOR ${ }^{1}$, Szilárd BodÓ ${ }^{1}$, László RózSA ${ }^{1}$, József RÁTKY ${ }^{2}$, \\ Attila ZSOLNAI ${ }^{*}$ and István ANTON ${ }^{1}$ \\ ${ }^{1}$ NARIC Research Institute for Animal Breeding, Nutrition and Meat Science, \\ Gesztenyés u. 1, H-2053 Herceghalom, Hungary; ${ }^{2}$ Department of Obstetrics and \\ Reproduction, University of Veterinary Medicine, Budapest, Hungary
}

(Received 21 January 2019; accepted 2 May 2019)

The aim of this study was to reveal the effect of single-nucleotide polymorphisms (SNPs) on the total number of piglets born (TNB), the litter weight born alive (LWA), the number of piglets born dead (NBD), the average litter weight on the 21st day (M21D) and the interval between litters (IBL). Genotypes were determined on a high-density Illumina Porcine SNP 60K BeadChip. Data screening and data identification were performed by a multi-locus mixed-model. Statistical analyses were carried out to find associations between individual genotypes of 290 Hungarian Large White sows and the investigated reproduction parameters. According to the analysis outcome, three SNPs were identified to be associated with TNB. These loci are located on chromosomes 1,6 and $13\left(-\log _{10} \mathrm{P}=\right.$ 6.0, 7.86 and 6.22, the frequencies of their minor alleles, MAF, were 0.298, 0.299 and 0.364 , respectively). Two loci showed considerable association $\left(-\log _{10} \mathrm{P}=\right.$ 10.35 and 10.46) with LWA on chromosomes 5 and X, the MAF were 0.425 and 0.446 , respectively. Seven loci were found to be associated with NBD. These loci are located on chromosomes $5,6,13,14,15,16$ and $18\left(-\log _{10} \mathrm{P}=10.95,5.43\right.$, $8.29,6.72,6.81,5.90$, and 5.15, respectively). One locus showed association $\left(-\log _{10} \mathrm{P}=5.62\right)$ with M21D on chromosome 1 (the MAF was 0.461$)$. Another locus was found to be associated with IBL on chromosome $8\left(-\log _{10} \mathrm{P}=7.56\right.$; the MAF was 0.438 ). The above-mentioned loci provide a straightforward possibility to assist selection by molecular tools and, consequently, to improve the competitiveness of the Hungarian Large White (HLW) breed.

Key words: Hungarian Large White sows, SNP, reproduction parameters

Pigs have played an economically important role in the Carpathian Basin since ancient times. Archaeological findings and documents demonstrate the presence of pig keepers from the period of the House of Árpád kings. Later, at the time of the Turkish occupation, basically primitive breeds of various colours were kept which looked similar to wild boars (Horn et al., 1976). Breeding of

*Corresponding author; E-mail: attila.zsolnai@gmail.com 
Mangalica pigs started after the industrial revolution in the 1830 s, when this fatty breed became very popular for its great taste. Raising of the Hungarian Large White (HLW) breed dates back to the early 1900s when an increased demand arose for leaner and more rapidly growing breeds.

The ancestors of HLW pigs were the English Large White, the Deutsches Edelschwein, the English Middle White and the Swedish Yorkshire breeds. The herd-book of the HLW breed was established about one hundred years ago. When developing the HLW, breeders focused on increased reproductive performance, high growth potential, favourable feed conversion rate, robustness, good adaptability, increased stress tolerance, and outstanding meat quality (Horn et al., 2011)

These pigs are commonly used in crossbreeding or hybrid programmes and have been noted for their large litter size, good milk production and excellent maternal instincts. Despite their good lifetime performance, production parameters and crossbreeding ability, in the last decades HLW pigs could not compete with the Western European hybrids in terms of production results. A possible reason for this handicap could be the relatively lower values of reproductive trait parameters. Breed improvement is extremely important in obtaining high-yielding animals of greater performance.

Selection decisions are based on estimated breeding values (EBVs), which are estimates of the genetic merit of pigs. EBVs are derived from pedigree and performance data available from herd recording systems for a number of performance and reproductive traits. The genetic gain that has been achieved in a population of pigs is demonstrated through genetic trends, which show the average EBV of all animals born in the same year (https://www.dpi.nsw.gov.au/_data/ assets/pdf_file/0008/45566/Breeds_of_pigs_-_Large_White_-_Primefact_62-final. pdf).

In the past few years the development of molecular genetics has led to the possibility of genomic testing in livestock as well. Genome-wide association study (GWAS) experiments based on the typing of single-nucleotide polymorphisms (SNPs) are suitable for finding loci associated with different reproduction traits in pig breeds.

Muñoz et al. (2007) investigated the effect of ESR1 and ESR2 polymorphisms on the total number of piglets born (TNB) and the number of piglets born alive (NBA) in a Chinese-European pig line. According to their results, the ESR1 c1227T allele was significantly associated with the TNB. The additive substitution effect was estimated to be 0.40 piglets born per litter $(\mathrm{P}<0.03)$, and no dominance effects were observed.

Onteru et al. (2011) found in their GWAS experiment several informative quantitative trait locus (QTL) regions and genes to be associated with lifetime reproductive traits, including lifetime total number born (LTNB) and lifetime number born alive (LNBA). Many of the QTL regions showing association with 
reproductive traits coincided with previously identified QTL for fat deposition. This fact reinforces the role of fat regulation for lifetime reproductive traits.

In a GWAS, Uimari et al. (2011) identified SNPs associated with reproduction traits in the Finnish Landrace breed. There were statistically significant results $\left(-\log _{10} \mathrm{P}\right.$ value $\left.>5.70\right)$ for TNB in the first and later parities and piglet mortality between birth and weaning in later parities. Overall, three separate regions on chromosome 9 gave significant results for litter size and pig mortality. The frequencies of favourable alleles of the significant SNPs are moderate in the Finnish Landrace population.

Lei et al. (2011) identified one SNP in the miR-27a gene which proved to be associated with litter size in Large White pigs.

Onteru et al. (2012) performed a GWAS for reproductive traits in commercial sows. The investigated traits were TNB, NBA, number of stillborn (SB), number of mummified fetuses at birth (MUM) and gestation length (GL) in each of the first three parities. The genomic regions (SLC22A18 on SSC2) containing genes important for fetal developmental and uterine functions were associated with TNB and NBA in the first two parities. QTL in other fetal developmental genes were associated with SB and MUM in different parities.

Han et al. (2012) examined polymorphisms of the secreted phosphoprotein 1 (SPP1) gene and its association with growth and carcass traits in the $\mathrm{F} 2$ population of the crossbred Landrace $\times$ Jeju (Korea) Black pig. The SPP1 A/B heterozygous pigs had significantly higher body weight at birth and on days 21 and 70, and a higher level of average daily gain during the early developmental period than was seen in the $\mathrm{A} / \mathrm{A}$ and $\mathrm{B} / \mathrm{B}$ homozygous pigs $(\mathrm{P}<0.05)$.

Xiao-Lei et al. (2012) analysed 820 commercial pigs in a GWAS in order to find associations between reproductive traits (TNB and NBA) and SNPs. They described five common regions which were significantly associated with both traits on SSC1, 3, 13, and 16.

In their study on Large White (LW) and Landrace (L) pigs, BergfelderDrüing et al. (2015) found 17 different significant markers affecting NBA in regions with known effects on female reproduction. No overlapping significant chromosome areas or QTL between the two breeds were detected.

In a GWAS, Schneider et al. (2015) identified several quantitative trait loci (QTL) for SB piglets ignoring the last piglet born (1 QTL), number of stillborn piglets in the last birth position (1 QTL), and percent of stillborn ignoring the last piglet (3 QTL).

Baginé Hunyadi et al. (2016) investigated the effect of seven genes on reproductive traits in Hungarian Large White sows. According to the outcome of their study the epidermal growth factor gene (EGF) had a significant impact on TNB and NBA.

Sato et al. (2016) tested $347 \mathrm{LW}$ sows to find an association between SNPs and prolificacy traits. Seven genes were found to be associated with TNB. Six of 
the seven genes were associated with reproductive traits, including TNB, NBA and average weight of piglets at weaning (AWW).

He et al. (2016) found large phenotypic variations in litter size among Chinese Erhualian sows. Significant differences in TNB and the number of corpora lutea were observed between sows with high and low EBVs for TNB. Genome-wide fixation coefficient (FST) values (otherwise called genetic distance of a given marker between two groups) were calculated for each SNP between the high- and low-EBV groups. Forty genes were identified around the top 10 highest FST SNPs, of which UCHL1, RPS6KB1 and CLTC were reported to affect ovulation rate in pigs.

Kang et al. (2017) identified five genome-wide suggestive SNP markers for the LTNB piglets and final parity. All five of these markers were highly associated with other sow lifetime productivity-related traits, and all these markers were located within or near one particular gene, MEGF11 (multiple epidermal growth factor-like domains protein 11), on chromosome 1.

Wang et al. (2017) were looking for associations between the FUT2 gene and production and reproductive traits (age at $100 \mathrm{~kg}$, backfat thickness at $100 \mathrm{~kg}$, eye muscle thickness, number of newborn piglets, number of weaned piglets, and birth weight) in Large White sows. They detected one SNP in the intron of FUT2 to be significantly associated with the number of newborn piglets and weaned piglets.

Uzzaman et al. (2018) performed a GWAS on Yorkshire sows for reproductive traits (NBA, TNB, the weight shortfall number, the total number of suckling piglets, and the number of pigs weaned). They identified a total of 15 SNPs of which only one reached the Bonferroni level of significance $\left(-\log _{10} \mathrm{P}>6.63\right)$, and fourteen SNPs were suggestive of being associated with the reproductive traits of interest $\left(-\log _{10} \mathrm{P}>4.30\right)$.

Wang et al. (2018) conducted a GWAS in LW pigs for 7 reproductive traits [TNB, NBA, LWA, average birth weight (ABW), gestation length (GL), age at first service (AFS), age at first farrowing (AFF)]. They identified 12 genomewide significant and 41 suggestive significant SNPs associated with 6 reproductive traits.

Suwannasing et al. (2018) used single-step GWAS (ssGWAS) for detecting genomic regions having an influence on reproductive traits (the number of pigs weaned per sow per year - PWSY, the number of litters per sow per year LSY, pigs weaned per litter - PWL, born alive per litters - BAL, non-productive days - NPD, and wean to conception interval per litter - W2CL in L and LW sows. They identified 25 (L) and 22 (LW) SNPs associated with reproductive traits. Retinol binding protein 7 and ubiquitination factor E4B were identified as candidate genes for PWL, BAL, W2CL, and PWSY and a solute carrier organic anion transporter family member 6A1 gene for LSY and NPD. 
To explore the genetic mechanism of litter traits, Wu et al. (2018a) conducted several ssGWAS in L and LW sows. ssGWAS was performed separately for each breed and each parity due to population stratification and temporal gene effect. The results indicated 22 crucial SNPs (affecting TNB, NBA and LWB) and four interesting candidate genes (affecting embryonic development) related to litter traits across six parities.

For the identification of SNPs associated with litter traits in domestic pigs, $\mathrm{Wu}$ et al. (2018b) conducted a GWAS. The examined litter traits were TNB, NBA and litter weight born alive (LWB). Executing the genome-wide association analysis (at 5\% significance level) a single-step genomic BLUP approach (ssGBLUP) was used. A total of 8, 23 and 20 significant SNPs were associated with TNB, NBA and LWB, respectively.

The aim of the present study was to reveal the effect of single-nucleotide polymorphisms (SNPs) on the total number of piglets born (TNB), the litter weight born alive (LWA), the number of piglets born dead (NBD), the average litter weight on the 21st day (M21D) and the interval between litters (IBL).

\section{Materials and methods}

\section{Samples and genotyping}

A total of 300 blood samples from Hungarian Large White pigs on 11 farms were collected and stored at $-20^{\circ} \mathrm{C}$ until DNA extraction. Samples were chosen considering the following criteria: (i) having high or low values regarding reproduction parameters, and (ii) maximising the representativeness of the population. The latter criterion is based on selecting animals which are least related to each other based on their pedigree. DNA typing was performed on highresolution SNP chips developed for pigs (GeneSeek ${ }^{\circledR}$ Genomic Profiler ${ }^{\mathrm{TM}}$ HighDensity; Illumina Porcine SNP 60K BeadChip). Genotyping of the collected samples was performed by Neogen Europe Ltd., Scotland, UK. Reproduction data and breeding parameters of sows (including TNB, LWA, NBD, M21D and IBL) were collected from the database of HLW breeders.

\section{Data evaluation}

Samples were excluded from analysis if the call rate was below 95\%. Only SNPs having consistently high call rates $(>95 \%)$ were included in this study. Duplicate samples (Identity By Descent, IBD $>0.95$ ) were excluded from the dataset. After excluding monomorphic loci and loci with a MAF $<0.05$, the final dataset included 290 animals and 56,592 SNPs. For data screening and identification of loci associated with the reproductive traits included in this study, multilocus mixed-models were used. Phenotypic values were left as they were a con- 
tinuous variable. The genomic inflation factor, lambda value was calculated from the median of the distribution of the chi-square statistic from results divided by the median of the corresponding (ideal) chi-square distribution (Armitage, 1955). For the correction of population structure, genomic kinship matrix was used in a multi-locus mixed model (Segura et al., 2012). The used model was: $\mathrm{y}=\mathrm{X} \beta+$ $\mathrm{Zu}+\mathrm{e}$, where $\mathrm{y}$ is the phenotypic value, $\mathrm{X}$ is the matrix of fixed effects composed of SNPs and covariates (age and farm), $\mathrm{Z}$ is the matrix of random animal effects, e means the residual effects, and $\beta$ and $u$ are vectors representing coefficients of fixed and random effects, respectively.

All data formatting, filtering and statistical analyses were performed by the SVS software (GoldenHelix, US). Nearby genes of the identified SNPs were located by Sus scrofa Assembly Build 11.1. database.

\section{Results and discussion}

According to the analytical outcome of the present study, three SNPs were identified to be associated with TNB. These loci are located on SSC 1, 6 and 13 (Fig. 1, Table 1).

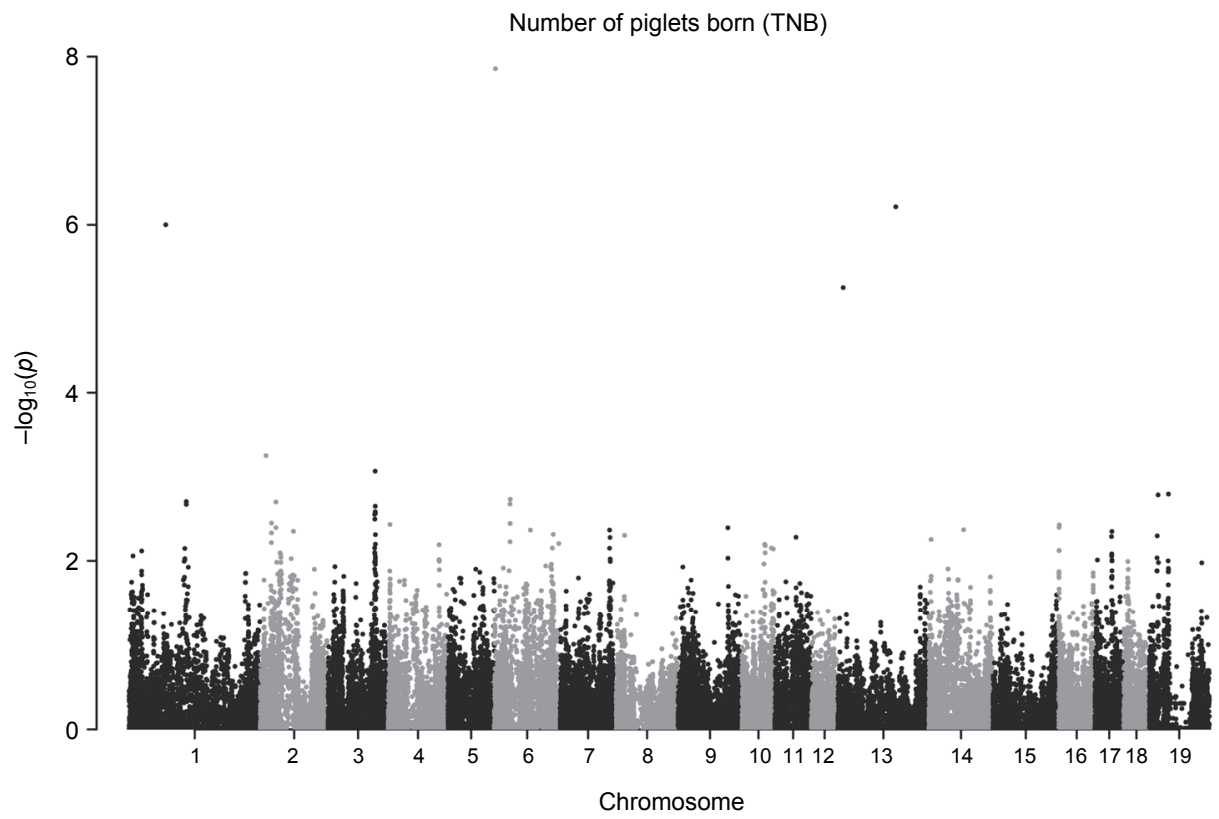

Fig. 1. Manhattan plot of single-nucleotide polymorphisms (SNPs) regarding the total number of piglets born (TNB). Loci on chromosomes 1,6 and 13 display the highest $-\log _{10} \mathrm{P}$ values (see dots $>6$ ) which are associated with TNB in Hungarian Large White (HLW) sows.

Number 19 on horizontal axis refers to chromosome X 
Table 1

List of loci associated with the total number of piglets born (TNB), their genomic location and nearest genes

\begin{tabular}{lccccc}
\hline Marker ss ID & $\begin{array}{c}\text { Position on } \\
\text { chromosomes }\end{array}$ & $-\log _{10} \mathrm{P}$ & $\begin{array}{c}\text { Candidate gene(s) } \\
\text { near the marker }\end{array}$ & MAF & FDR \\
\hline rs80878088 & $1: 88143914$ & 6.00 & RFPL4B, MARCKS, & 0.298 & 0.016 \\
rs336610321 & $6: 2594634$ & 7.86 & FBXO31, FOXL1, & & $6.88 \mathrm{e}-4$ \\
rs326153933 & $13: 139009753$ & 6.22 & MTHFSD & 0.299 & 0.015 \\
\hline
\end{tabular}

MAF: minor allele frequency; FDR: false discovery rate

SSC 1: Ret finger protein like 4B (RFPL4B) is derived by automated computational analysis referred by GenBank (RefSeqID: NC_010443.5). Its function is not known but the abundance of its RNA form is the highest in the testis and placenta in humans (Fagerberg et al., 2014). Myristoylated alanine rich protein kinase $\mathrm{C}$ substrate (MARCKS) protein is thought to be involved in cell motility, phagocytosis, membrane trafficking and mitogenesis (Arbuzova et al., 2002).

SSC 6: F-box protein 31 (FBXO31) is thought to bind and recruit substrate for ubiquitination and degradation (Zhang et al., 2015). Forkhead box L1 (FOXL1) is a member of the forkhead/winged helix-box (FOX) family of transcription factors. It plays a critical role in the regulation of multiple processes including metabolism, cell proliferation and gene expression during ontogenesis required for proper proliferation and differentiation in the gastrointestinal epithelium (https://www.genecards.org/cgi-bin/carddisp.pl?gene=FOXL1\&keywords=foxl1).

Copy numbers of the methenyltetrahydrofolate synthetase domain containing the MTHFSD gene presented positive correlations with the transcript level of MTHFSD gene in adult ovaries and significantly changed the litter size in Xiang pig population (Ran et al., 2018).

SSC 13: Fibroblast growth factor 12 (FGF12) pattern of DNA methylation revealed in oestrus and dioestrus has potential application value in regulating ovine oestrus (An et al., 2018). In a GWAS this gene was also pointed out as a candidate gene for endometritis in cows (Naderi et al., 2018).

Six loci were identified to be highly associated with LWA. These loci are located on SSC 5, 6, 14, 16, 17 and X (Fig. 2, Table 2).

SSC 5: Rho GTPase activating protein 8 (ARHGAP8) might be involved in twinning rate in Maremmana cattle (Moioli et al., 2017). Proline rich 5 (PRR5) plays an important role in expression regulation of platelet-derived growth factor receptor beta which is involved in embryonic development, angiogenesis, cell proliferation and differentiation and binge eating behaviour in humans (McElroy et al., 2018). 


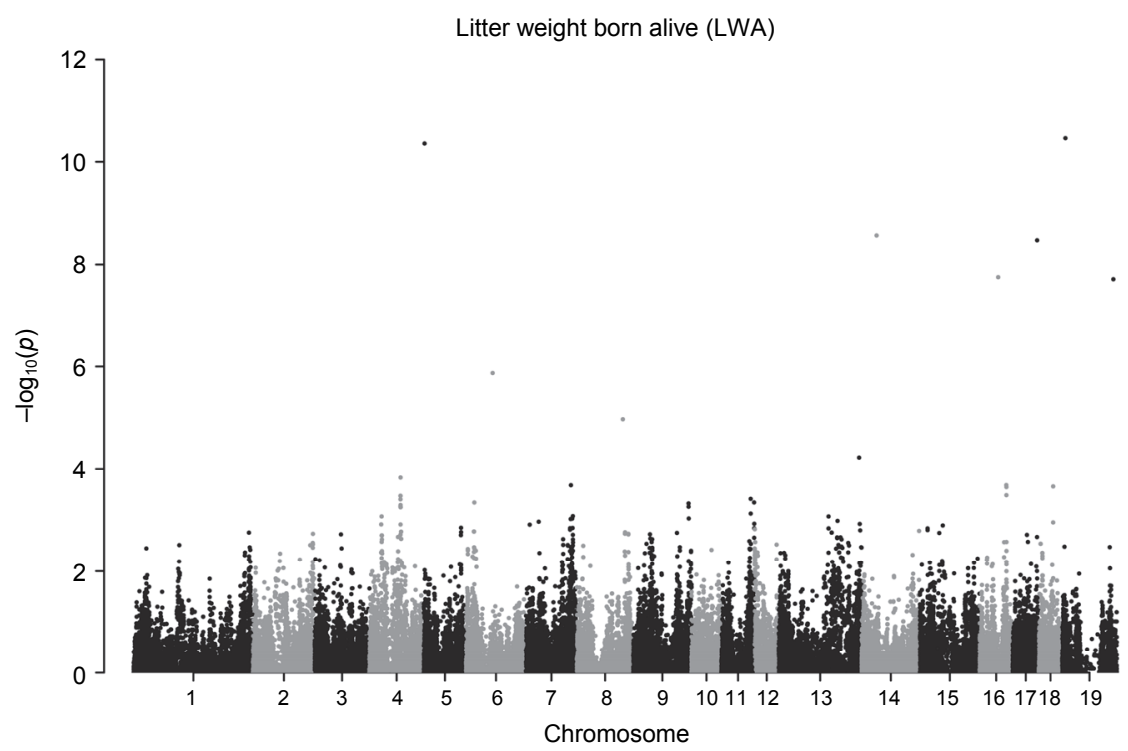

Fig. 2. Manhattan plot of SNPs regarding the litter weight born alive (LWA). Loci on chromosomes $5,6,14,16,17$ and $\mathrm{X}$ display the highest $-\log _{10} \mathrm{P}$ values (see dots $>5$ ) which are associated with LWA in HLW sows. Number 19 on horizontal axis refers to chromosome $\mathrm{X}$

Table 2

List of loci associated with litter weight born alive (LWA), their genomic location and nearest genes

\begin{tabular}{lcrccc}
\hline Marker ss ID & $\begin{array}{c}\text { Position on } \\
\text { chromosomes }\end{array}$ & $-\log _{10} \mathrm{P}$ & $\begin{array}{c}\text { Candidate gene(s) } \\
\text { near the marker }\end{array}$ & MAF & FDR \\
\hline rs81382693 & $5: 1912703$ & 10.35 & ARHGAP8, PRR5 & 0.425 & $1.10 \mathrm{e}-06$ \\
rs340060083 & $6: 70048043$ & 5.87 & PADI2, PADI1 & 0.397 & $9.49 \mathrm{e}-03$ \\
rs345681434 & $14: 39399038$ & 8.56 & MED13L, TBX3 & 0.115 & $4.53 \mathrm{e}-05$ \\
rs81459332 & $16: 48711236$ & 7.76 & ERBB2IP & 0.155 & $1.74 \mathrm{e}-04$ \\
rs80882327 & $17: 57391800$ & 8.47 & BMP7 & 0.492 & $4.22 \mathrm{e}-05$ \\
rs81473286 & X: 8718698 & 10.46 & AMELX, ARHGAP6 & 0.446 & $1.73 \mathrm{e}-06$ \\
rs319594780 & X: 135147279 & 7.72 & SLITRK cluster & 0.348 & $1.59 \mathrm{e}-04$ \\
\hline
\end{tabular}

MAF: minor allele frequency; FDR: false discovery rate

SSC 6: Peptidyl arginine deiminase 2 (PADI2) is known to be involved in metabolic pathways, to have a strong correlation with a haplotype shared by multiple high angiogenic mouse strains. In addition, inhibition of PADI2 demonstrated a dosage-dependent effect in HMVECs (Khajavi et al., 2017). PADI1 is part of the peptidylarginine deiminase gene clusters. In diethylstilboestrol- (DES-) administered mice a high density of oestrogen receptor alpha dependent super-enhancer was identified in the PADI gene cluster. Data suggested that DES alters uterine development and consequently adult reproductive function by modifying the enhanc- 
er landscape at ER $\alpha$ binding sites near oestrogen-regulated genes (Jefferson et al., 2018). It has also been shown that PADI1-catalysed histone citrullination is essential for early embryo development in the mouse (Zhang et al., 2016).

SSC 14: Mediator complex subunit 13 like (MED13L) is a mediator complex component; MED13 regulates zygotic genome activation and is required for postimplantation development in the mouse (Miao et al., 2018). In humans it is involved in congenital cardiac and neurodevelopmental deficits (Adegbola et al., 2015). Tbox 3 (TBX3) has been found to be associated with NBD (Onteru et al., 2012).

SSC 16: Erbb2 interacting protein (ERBB2IP or ERBIN) is one of the candidate genes affecting litter size of German sows (Spötter et al., 2010).

SSC 17: Bone morphological protein 7 (BMP7) is an osteoinductive protein and is linked to NBA and litter weight at birth and the litter weight at 21 days (Feng et al., 2013).

SSC X: Beside sex determination (Fontanesi et al., 2008), the amelogenin $\mathrm{X}$-linked gene (AMELX) also plays a role in osteoclastogenesis in pigs (Hatakeyama et al., 2006). Rho GTPase activating protein 6 (ARHGAP6) is colocalised with QTLs for fatness and growth traits (Puig-Oliveras et al., 2016). SLIT and NTRK Like Family Member 2 (SLITRK2) is involved in synaptogenesis and promotes excitatory synapse differentiation (Beaubien et al., 2016).

Seven loci were found to be associated with NBD. These loci are located on chromosomes 5, 6, 13, 14, 15, 16 and 18 (Fig. 3, Table 3).

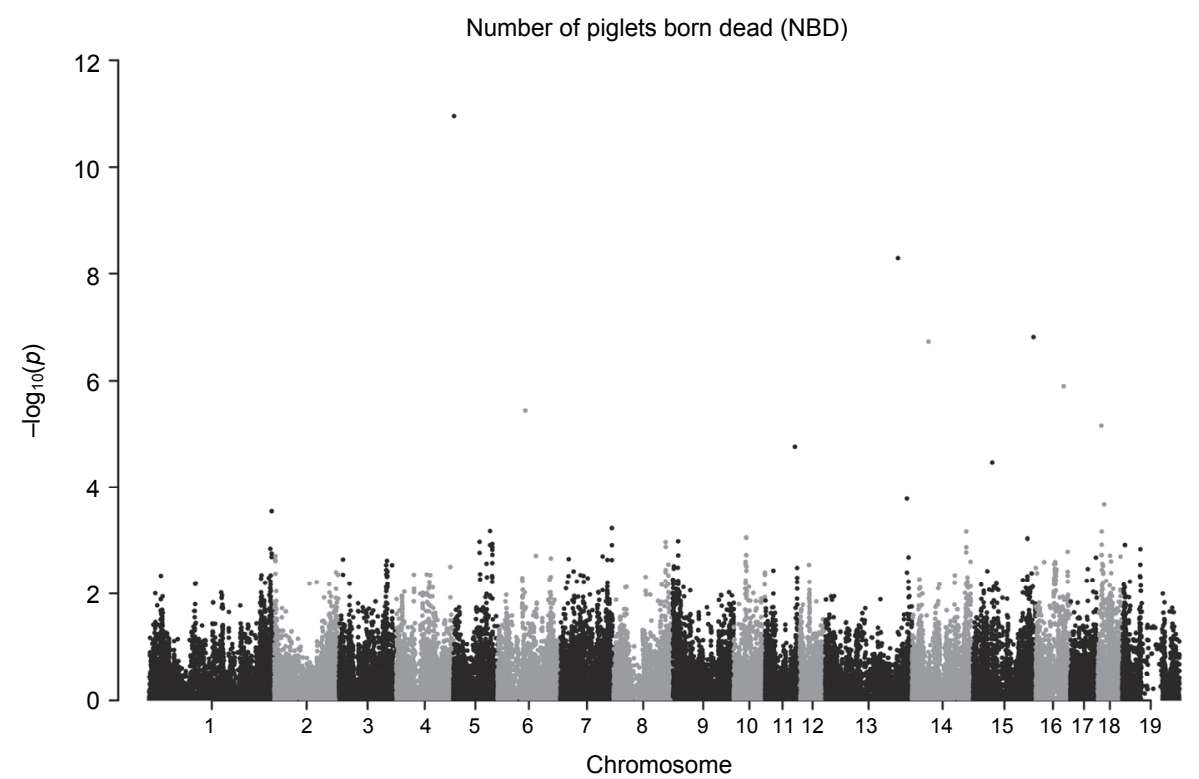

Fig. 3. Manhattan plot of SNPs associated with the number of piglets born dead (NBD). Loci on chromosomes $5,6,13,14,15,16$ and 18 display the highest $-\log _{10} \mathrm{P}$ values (see dots $>5$ ) which are associated with NBD in HLW sows. Number 19 on horizontal axis refers to chromosome X 
Table 3

List of loci associated with the number of piglets born dead (NBD), their genomic location and nearest genes

\begin{tabular}{lccccc}
\hline Marker ss ID & $\begin{array}{c}\text { Position on } \\
\text { chromosomes }\end{array}$ & $-\log _{10} \mathrm{P}$ & $\begin{array}{c}\text { Candidate gene(s) } \\
\text { near the marker }\end{array}$ & MAF & FDR \\
\hline rs81382693 & $5: 1912703$ & 10.95 & ARHGAP8 & 0.425 & $5.56 \mathrm{e}-07$ \\
rs340060083 & $6: 70048043$ & 5.43 & PADI2, PADI1 & 0.397 & $3.03 \mathrm{e}-02$ \\
rs80893810 & $13: 183254699$ & 8.29 & CADM2, SNORA70, & & \\
& & & LIPI & 0.335 & $1.27 \mathrm{e}-04$ \\
rs80845657 & $14: 41396206$ & 6.72 & RPL6, TBX3 & 0.095 & $2.35 \mathrm{e}-03$ \\
rs329723588 & $15: 152057161$ & 6.81 & SCLY & 0.090 & $2.58 \mathrm{e}-03$ \\
rs338594773 & $16: 70502947$ & 5.90 & EBF1 & 0.365 & $1.24 \mathrm{e}-02$ \\
rs333328959 & $18: 8927486$ & 5.15 & BRAF, MKRN1, PPAR & 0.069 & $4.99 \mathrm{e}-02$ \\
\hline
\end{tabular}

MAF: minor allele frequency; FDR: false discovery rate

SSC 5 and 6: see description after discussion of LWA-associated hits (Table 2).

SSC 13: Cell adhesion molecule 2 (CADM2) regulates body weight and energy homeostasis in mice (Yan et al., 2018), and has been found to be associated with habitual physical activity in humans. Small Nucleolar RNA, H/ACA Box 70 (SNORA70) is one of the genes where selection signature was detected among several cattle breeds (Taye et al., 2017), while the possible function of lipase I (LIPI) is to produce lysophosphatidic acid which is an important mediator of multiple biological functions (Aoki et al., 2007).

SSC 14: Ribosomal protein L6 (RPL6) interacts with histones and takes part in DNA damage response (Yang et al., 2018), while T-box 3 (TBX3) has been found to be associated with NBD (Onteru et al., 2012).

SSC 15: Expression of selenocysteine lyase (SCLY) is related to amino acid transport and metabolism in the endometrium and to the receptive status of the cow (França et al., 2017). It has also been found to be coupled with an obesity trait in mice (Seale et al., 2015).

SSC 16: Early B cell factor 1 (EBF1) takes part in a micro RNA attenuated lipogenic gene expression cascade via downregulation of EBF1 to different extents depending on the breed of gilts (Taniguchi et al., 2014).

SSC 18: B-Raf proto-oncogene, serine/threonine kinase (BRAF) was found to be under selection comparing Berkshire and Korean native breeds (Edea and Kim, 2014); makorin ring finger protein 1 (MKRN1) is a stress granule-resident protein (Cassar et al., 2015) and can degrade the central regulator of adipogenesis; peroxisome proliferator activated receptor (MKRN1) is a nuclear receptor linked to obesity and metabolic diseases (Kim et al., 2014). 
When comparing LWA and NBD, a similarity could be noticed concerning loci located on chromosomes 5 and 6 . A possible explanation for this similarity is the fact that large litter size leads to lower average birth weights, with more piglets born weighing less than $1 \mathrm{~kg}$, resulting in a negative impact on piglet viability and growth performance (Magnabosco et al., 2016).

The only locus found to be associated with M21D was situated on chromosome 1 (Fig. 4, Table 4).

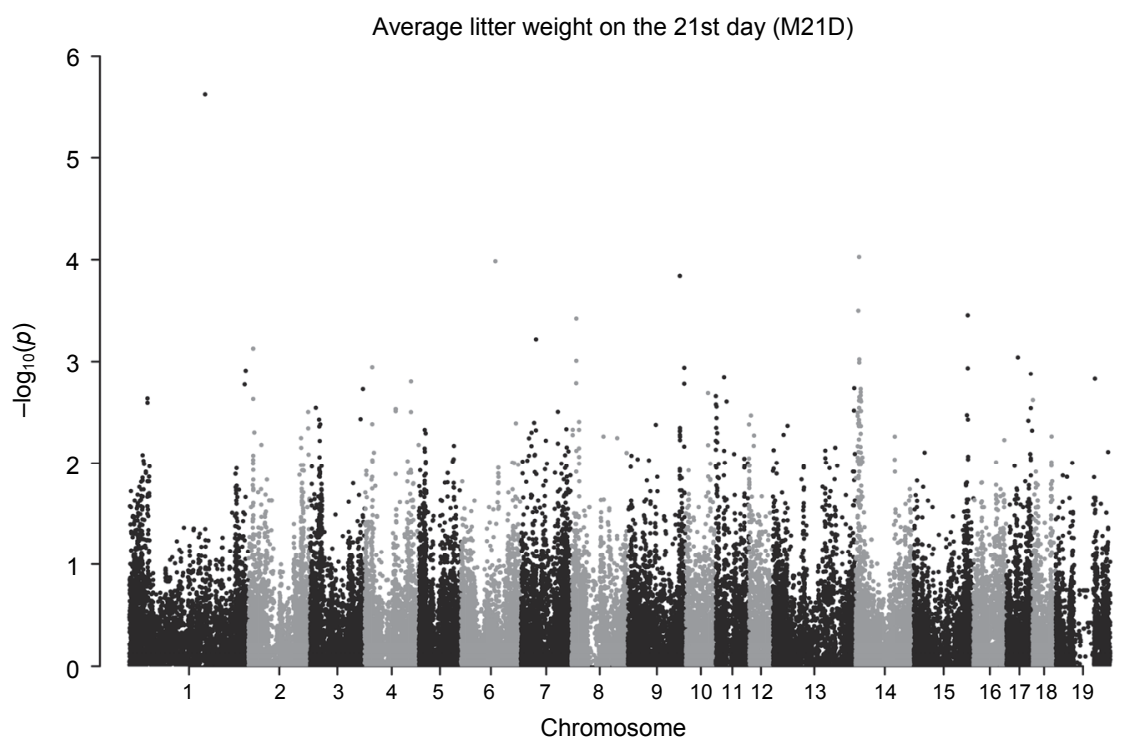

Fig. 4. Manhattan plot of the only locus associated with the average litter weight on the 21 st day

(M21D). This SNP is located on chromosome 1 and displays the highest $-\log _{10} \mathrm{P}$ value (see dot $>5$ ). Number 19 on horizontal axis refers to chromosome $\mathrm{X}$

Table 4

The locus associated with average litter weight on the 21st day (M21D), its genomic location and nearest genes

\begin{tabular}{lccccc}
\hline Marker ss ID & $\begin{array}{c}\text { Position on } \\
\text { chromosomes }\end{array}$ & $-\log _{10} \mathrm{P}$ & $\begin{array}{c}\text { Candidate gene(s) } \\
\text { near the marker }\end{array}$ & MAF & FDR \\
\hline rs699316219 & $1: 200350940$ & 5.62 & ARF6, ABHD12B & 0.461 & 0.117 \\
\hline
\end{tabular}

MAF: minor allele frequency; FDR: false discovery rate

SSC 1: ADP ribosylation factor 6 (ARF6) is ubiquitous in all porcine tissues examined, with the highest levels in kidney and stomach and the lowest levels in muscle and heart (Zhang et al., 2010). The abhydrolase domain containing 12B (ABHD12B) is a candidate gene for obesity in pigs (Kogelman et al., 2015). 
In the case of IBL, like for M21D, a sole SNP was found to be associated with this parameter which is located on chromosome 8 (Fig. 5, Table 5).

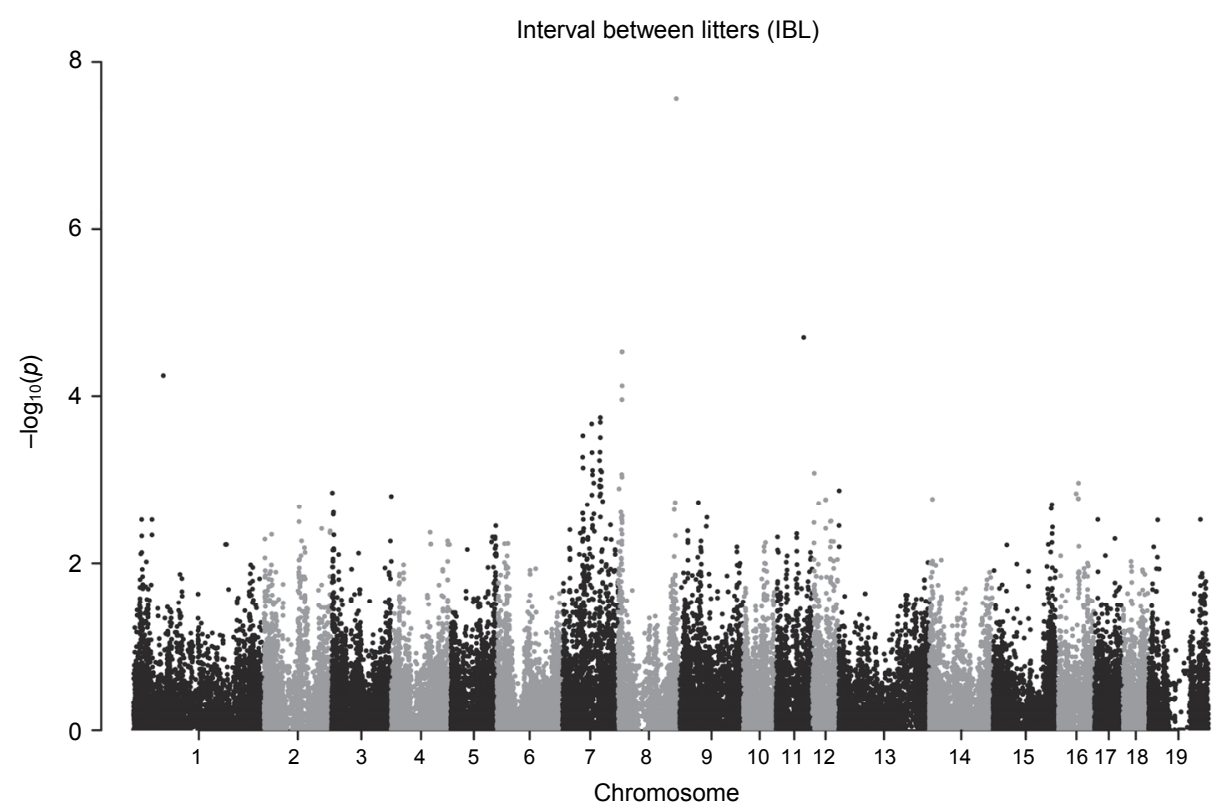

Fig. 5. Manhattan plot of the only locus associated with the interval between litters (IBL). This SNP is located on chromosome 8 and displays the highest $-\log _{10} \mathrm{P}$ value (see dot $>7$ ).

Number 19 on horizontal axis refers to chromosome $\mathrm{X}$

Table 5

The locus associated with the interval between litters (IBL), its genomic location and nearest genes

\begin{tabular}{lccccc}
\hline Marker ss ID & $\begin{array}{c}\text { Position on } \\
\text { chromosomes }\end{array}$ & $-\log _{10} \mathrm{P}$ & $\begin{array}{c}\text { Candidate gene(s) } \\
\text { near the marker }\end{array}$ & MAF & FDR \\
\hline rs81301813 & $8: 140274549$ & 7.56 & PKD2, SPP1, MAPK10 & 0.438 & $1.35 \mathrm{e}-03$
\end{tabular}

MAF: minor allele frequency; FDR: false discovery rate

SSC 8: Polycystin 2, transient receptor potential cation channel (PKD2) takes part in many processes including aortic development, regulation of the calcium-release channel, embryonic placenta development, etc. (https://www. uniprot. org/uniprot/F2VYA1). Secreted phosphoprotein 1 (SPP1) is related to body weight at birth and on days 21 and 70, and to the higher level of average daily gain during the early developmental period (Han et al., 2012). Mitogen-activated protein kinase 10 (MAPK10) is one of the candidate genes affecting litter size of German sows (Spötter et al., 2010). 
Several SNPs found in this study are in the regions highlighted by other investigations:

SSC1, rs 80878088 is coupled to TNB (within 4 million base pairs, bp, from FOXO3 associated with NBA (Wu et al., 2018b).

SSC8, rs81301813 is coupled to TBL (approximately 36,000 bp from SPP1 associated with weight, gain and carcass properties (Han et al., 2012).

SSC14, rs345681434 is coupled to LWA (within half million bp from TBX3 associated to NBA (Onteru et al., (2012). On the same chromosome, SSC14, same region, rs80845657 coupled to NBD is 1.36 million bp far from TBX3.

SSC16, rs81459332 is coupled to LWA (approximately 2.6 million bp from HTR1A) associated with NBA (Onteru et al., 2012).

SSC18, rs333328959 is coupled to NBD (approximately 1.2 million bp from EPHB6) associated with LSY and NPD (Suwannasing et al., 2018).

SSCX, rs319594780 is coupled to LWA (within 1 million bp from SLITRK2) associated with BAL and W2CL (Suwannasing et al., 2018).

A detailed enumeration of SNPs and candidate genes found by other teams while investigating similar parameters is as follows:

He et al. (2016) identified 10 SNPs associated with reproductive parameters. Five of them (rs81399474, rs81400131 and rs81405013 on SSC8 and rs81434499 and rs81434489 on SSC 12) corresponded to previously reported QTL for litter size. The other five SNPs (rs81367039 on SSC2, rs80891106 on SSC7, rs81477883 on SSC12, and rs80938898 and rs80971725 on SSC14) were novel QTL for TNB. Significant associations between rs81399474 on SSC8 and TNB were confirmed in 313 Erhualian sows. Forty genes were identified around the top 10 highest FST SNPs, of which UCHL1, adjacent to rs81399474, and RPS6KB1 and CLTC, adjacent to rs81434499, have been reported to affect the ovulation rate in pigs.

Wang et al. (2017) revealed significant associations between a singlenucleotide polymorphism (rs345476947, $\mathrm{C} \rightarrow \mathrm{T}$ ) in the intron of the FUT2 gene and the number of newborns and weaned piglets.

Uzzaman et al. (2018) described two significant SNPs, rs81465399 (P = 8.05E-08) and rs80991683 ( $\mathrm{P}=1.55 \mathrm{E}-06)$ on SSC17 which were associated with weight shortfall number. In addition, SNP rs81356596 (P = 1.20E-05) on SSC2 was associated with the total number of suckling piglets. Another two SNPs, rs81454514 $(\mathrm{P}=1.07 \mathrm{E}-05)$ and rs81454465 $(\mathrm{P}=1.56 \mathrm{E}-05)$ on SSC15 associated with NBA were located near the reported QTL region of both the NBA and TNB traits.

Based on the results obtained by Wang et al. (2018), 14 genes (BHLHA15, OCM2, IL1B2, GCK, SMAD2, HABP2, PAQR5, GRB10, PRELID2, DMKN, GPI, GPIHBP1, ADCY2 and ACVR2B) were regarded as important candidates for swine reproductive traits because of their critical roles in embryonic development, energy metabolism and growth development. 
Suwannasing et al. (2018) identified five genes as candidate genes in LW pigs, two of which (aldehyde dehydrogenase 1 family member A3 and leucinerich repeat kinase 1) were associated with all of six reproduction traits (PWSY, LSY, PWL, BAL, NPD and W2CL) and three genes (retrotransposon Gag like 4, transient receptor potential cation channel subfamily $\mathrm{C}$ member 5, and LHFPL tetraspan subfamily member 1) with five traits except W2CL.

$\mathrm{Wu}$ et al. (2018a) identified four interesting candidate genes (FBXL7, ALDH1A2, LEPR and DDX1) associated with litter traits in different parities that have a major effect on embryonic development progression. At SSC1, the AIM1 and FOXO3 genes were found to be associated with NBA. These genes increase ovarian reproductive capacity and follicle numbers and decrease gonadotropin levels. The genes SLC36A4 and INTU, which are involved in cell growth, cytogenesis and development, were found to be associated with LWB. Furthermore, significant SNPs were found on SSC 14, 13, 9 and 5 in association with TNB, NBA, and LWB (Wu et al., 2018b).

Whyte et al. (2018) demonstrated the importance of the IL1B2 gene in protein expression increase during the period of conceptus elongation in pigs.

In conclusion, genetic analysis can facilitate direct selection among alleles of the SNPs highlighted in this study; however, selection decisions depend on economic goals and are usually taken by breeding associations based on EBVs. A possible marker-assisted selection (MAS) approach - such as selecting for favourable alleles at reported loci at the chromosomes mentioned above - might be performed if higher TNB, LWA, M21D and lower NBD, IBL are desirable. Hereby we suggest that the results described here should be incorporated by the Hungarian LW breeders in current and future breeding programmes, and by authorities in the pig breeding strategy adopted by the government.

\section{Acknowledgement}

Financial support from the Ministry of Agriculture $(\mathrm{MgF} / 754 / 2017)$ is gratefully acknowledged.

\section{References}

Adegbola, A., Musante, L., Callewaert, B., Maciel, P., Hu, H., Isidor, B., Picker-Minh, S., Le Caignec, C., Delle Chiaie, B., Vanakker, O., Menten, B., Dheedene, A., Bockaert, N., Roelens, F., Decaestecker, K., Silva, J., Soares, G., Lopes, F., Najmabadi, H., Kahrizi, K., Cox, G. F., Angus, S. P., Staropoli, J. F., Fischer, U., Suckow, V., Bartsch, O., Chess, A., Ropers, H. H., Wienker, T. F., Hübner, C., Kaindl, A. M. and Kalscheuer, V. M. (2015): Redefining the MED13L syndrome. Eur. J. Hum. Genet. 23, 1308-1317.

An, X., Ma, H., Han, P., Zhu, C., Cao, B. and Bai, Y. (2018): Genome-wide differences in DNA methylation changes in caprine ovaries between oestrous and dioestrous phases. J. Anim. Sci. Biotechnol. 9, 85 . 
Aoki, J., Inoue, A., Makide, K., Saiki, N. and Arai, H. (2007): Structure and function of extracellular phospholipase A1 belonging to the pancreatic lipase gene family. Biochimie 89, 197-204.

Arbuzova, A., Arndt, A., Schmitz, A. P. and Vergères, G. (2002): Cross-talk unfolded: MARCKS proteins. Biochem. J. 362, 1-12.

Armitage, P. (1955): Tests for linear trends in proportions and frequencies. Biometrics 11, 375-386.

Beaubien, F., Raja, R., Kennedy, T. E., Fournier, A. E. and Cloutier, J. F. (2016): Slitrk1 is localized to excitatory synapses and promotes their development. Sci. Rep. 6, 27343.

Baginé Hunyadi, Á., Balogh, P., Nagy, K. and Kusza, S. (2016): Association and polymorphism study of seven candidate genes with reproductive traits in three pig breeds in Hungary. Acta Biochim. Pol. 63, 359-364.

Bergfelder-Drüing, S., Grosse-Brinkhaus, C., Lind, B., Erbe, M., Schellander, K., Simianer, H. and Tholen, E. (2015): A genome-wide association study in Large White and Landrace pig populations for number of piglets born alive. PLoS One 10, 3 .

Cassar, P. A., Carpenedo, R. L., Samavarchi-Tehrani, P., Olsen, J. B., Park, C. J., Chang, W. Y., Chen, Z., Choey, C., Delaney, S., Guo, H., Guo, H., Tanner, R. M., Perkins, T. J., Tenenbaum, S. A., Emili, A., Wrana, J. L., Gibbings, D. and Stanford, W. L. (2015): Integrative genomics positions MKRN1 as a novel ribonucleoprotein within the embryonic stem cell gene regulatory network. EMBO Rep. 16, 1334-1357.

Edea, Z. and Kim, K. S. (2014): A whole genomic scan to detect selection signatures between Berkshire and Korean native pig breeds. J. Anim. Sci. Technol. 56, 23.

Fagerberg, L., Hallström, B. M., Oksvold, P., Kampf, C., Djureinovic, D., Odeberg, J., Habuka, M., Tahmasebpoor, S., Danielsson, A., Edlund, K., Asplund, A., Sjöstedt, E., Lundberg, E., Szigyarto, C. A., Skogs, M., Takanen, J. O., Berling, H., Tegel, H., Mulder, J., Nilsson, P., Schwenk, J. M., Lindskog, C., Danielsson, F., Mardinoglu, A., Sivertsson, A., von Feilitzen, K., Forsberg, M., Zwahlen, M., Olsson, I., Navani, S., Huss, M., Nielsen, J., Ponten, F. and Uhlén, M. (2014): Analysis of the human tissue-specific expression by genome-wide integration of transcriptomics and antibody-based proteomics. Mol. Cell. Proteomics 13, 397-406.

Feng, X., Xie, S. Y., Zhou, J. S., Sun, G. R., Lu, P. and Li, M. (2013): Polymorphisms of the bone morphogenetic protein 7 gene (BMP7) and association analysis with sow productive traits. Anim. Reprod. Sci. 142, 56-62.

Fontanesi, L., Scotti, E. and Russo, V. (2008): Differences of the porcine amelogenin X and Y chromosome genes (AMELX and AMELY) and their application for sex determination in pigs. Mol. Reprod. Dev. 75, 1662-1668.

França, M. R., da Silva, M. I. S., Pugliesi, G., Van Hoeck, V. and Binelli, M. (2017): Evidence of endometrial amino acid metabolism and transport modulation by peri-ovulatory endocrine profiles driving uterine receptivity. J. Anim. Sci. Biotechnol. 8, 54.

Han, S. H., Shin, K. Y., Lee, S. S., Ko, M. S., Oh, H. S. and Cho, I. C. (2012): Porcine SPP1 gene polymorphism association with phenotypic traits in the Landrace $\times$ Jeju (Korea) Black pig F2 population. Mol. Biol. Rep. 39, 7705-7709.

Hatakeyama, J., Philp, D., Hatakeyama, Y., Haruyama, N., Shum, L., Aragon, M. A., Yuan, Z., Gibson, C. W., Sreenath, T., Kleinman, H. K. and Kulkarni, A. B. (2006): Amelogeninmediated regulation of osteoclastogenesis, and periodontal cell proliferation and migration. J. Dent. Res. 85, 144-149.

He, L. C., Li, P. H., Ma, X., Sui, S. P., Gao, S., Kim, S. W., Gu, Y. Q., Huang, Y., Ding, N. S. and Huang, R. H. (2016): Identification of new single nucleotide polymorphisms affecting total number born and candidate genes related to ovulation rate in Chinese Erhualian pigs. Anim. Genet. 48, 48-54.

Horn, A. (1976): Animal Breeding Volume III. Pig Breeding, Poultry Breeding, Rabbit and Fur Animal Breeding, Fish Breeding [in Hungarian]. Mezőgazdasági Kiadó, Budapest.

Horn, P., Pászthy, Gy. and Bene, Sz. (2011): Pig Breeding [in Hungarian]. University of Kaposvár, University of West Hungary, Pannon University. 
Jefferson, W. N., Kinyamu, H. K., Wang, T., Miranda, A. X., Padilla-Banks, E., Suen, A. A. and Williams, C. J. (2018): Widespread enhancer activation via ER $\alpha$ mediates estrogen response in vivo during uterine development. Nucleic Acids Res. 46, 5487-5503.

Kang, J. H., Lee, E. A., Lee, S. H., Kim, S. H., Lee, D. H., Hong, K. C. and Park, H. B. (2017): Genome-wide association study for sow lifetime productivity related traits in a Landrace purebred population. Livest. Sci. 202, 21-24.

Khajavi, M., Zhou, Y., Birsner, A. E., Bazinet, L., Rosa Di Sant, A., Schiffer, A. J., Rogers, M. S., Krishnaji, S. T., Hu, B., Nguyen, V., Zon, L. and D'Amato, R. J. (2017): Identification of Padi2 as a novel angiogenesis-regulating gene by genome association studies in mice. PLoS Genet. 13, e1006848.

Kim, J. H., Park, K. W., Lee, E. W., Jang, W. S., Seo, J., Shin, S., Hwang, K. A. and Song, J. (2014): Suppression of PPAR $\gamma$ through MKRN1-mediated ubiquitination and degradation prevents adipocyte differentiation. Cell Death Differ. 21, 594-603.

Kogelman, L. J., Zhernakova, D. V., Westra, H. J., Cirera, S., Fredholm, M., Franke, L. and Kadarmideen, H. N. (2015): An integrative systems genetics approach reveals potential causal genes and pathways related to obesity. Genome Med. 7, 105.

Lei, B., Gao, S., Luo, L. F., Xia, X. Y., Jiang, S. W., Deng, C. Y., Xiong, Y. Z. and Li, F. E. (2011): A SNP in the miR-27a gene is associated with litter size in pigs. Mol. Biol. Rep. 38, 3725-3729.

Magnabosco, D., Bernardi, M. L., Wentz, I., Cunha, E. C. P. and Bortolozzo, F. P. (2016): Low birth weight affects lifetime productive performance and longevity of female swine. Livest. Sci. 184, 119-125.

McElroy, S. L., Winham, S. J., Cuellar-Barboza, A. B., Colby, C. L., Ho, A. M., Sicotte, H., Larrabee, B. R., Crow, S., Frye, M. A. and Biernacka, J. M. (2018): Bipolar disorder with binge eating behavior: a genome-wide association study implicates PRR5-ARHGAP8. Transl. Psychiatry 8, 40.

Miao, Y. L., Gambini, A., Zhang, Y., Padilla-Banks, E., Jefferson, W. N., Bernhardt, M. L., Huang, W., Li, L. and Williams, C. J. (2018): Mediator complex component MED13 regulates zygotic genome activation and is required for postimplantation development in the mouse. Biol. Reprod. 98, 449-464.

Moioli, B., Steri, R., Marchitelli, C., Catillo, G. and Buttazzoni, L. (2017): Genetic parameters and genome-wide associations of twinning rate in a local breed, the Maremmana cattle. Animal 11, 1660-1666.

Muñoz, G., Ovilo, C., Estellé, J., Silió, L., Fernández, A. and Rodriguez, C. (2007): Association with litter size of new polymorphisms on ESR1 and ESR2 genes in a Chinese-European pig line. Genet. Sel. Evol. 39, 195.

Naderi, S., Bohlouli, M., Yin, T. and König, S. (2018): Genomic breeding values, SNP effects and gene identification for disease traits in cow training sets. Anim. Genet. 49, 178-192.

Onteru, S. K., Fan, B., Du, Z. Q., Garrick, D. J., Stalder, K. J. and Rothschild, M. F. (2012): A whole-genome association study for pig reproductive traits. Anim. Genet. 43, 18-26.

Onteru, S. K., Fan, B., Nikkilä, M. T., Garrick, D. J., Stalder, K. J. and Rothschild, M. F. (2011): Whole-genome association analyses for lifetime reproductive traits in the pig. Anim. Sci. 89, 988-995.

Puig-Oliveras, A., Revilla, M., Castelló, A., Fernández, A. I., Folch, J. M. and Ballester, M. (2016): Expression-based GWAS identifies variants, gene interactions and key regulators affecting intramuscular fatty acid content and composition in porcine meat. Sci. Rep. 6, 31803.

Ran, X. Q., Pan, H., Huang, S. H., Liu, C., Niu, X., Li, S. and Wang, J. F. (2018): Copy number variations of MTHFSD gene across pig breeds and its association with litter size traits in Chinese indigenous Xiang pig. J. Anim. Physiol. Anim. Nutr. (Berl.) doi: 10.1111/ jpn. 12922. 
Sato, S., Kikuchi, T., Uemoto, Y., Mikawa, S. and Suzuki, K. (2016): Effect of candidate gene polymorphisms on reproductive traits in a Large White pig population, Anim. Sci. J. 87, 1455.

Schneider, J. F., Miles, J. R., Brown-Brandl, T. M., Nienaber, J. A., Rohrer, G. A. and Vallet, J. L. (2015): Genome wide association analysis for average birth interval and stillbirth in swine. J. Anim. Sci. 93, 529-540.

Schneider, J. F., Rempel, L. A., Snelling, W. M., Wiedmann, R. T., Nonneman, D. J. and Rohrer, G. A. (2012): Genome-wide association study of swine farrowing traits. Part II: Bayesian analysis of marker data. J. Anim. Sci. 90, 3360-3367.

Seale, L. A., Gilman, C. L., Hashimoto, A. C., Ogawa-Wong, A. N. and Berry, M. J. (2015): Dietinduced obesity in the selenocysteine lyase knockout mouse. Antioxid. Redox Signal 23, 761-774.

Segura, V., Vilhjálmsson, B. J., Platt, A., Korte, A., Seren, Ü., Long, Q. and Nordborg, M. (2012): An efficient multi-locus mixed-model approach for genome-wide association studies in structured populations. Nat. Genet. 44, 825-830.

Spötter, A., Hamann, H., Müller, S. and Distl, O. (2010): Effect of polymorphisms in four candidate genes for fertility on litter size in a German pig line. Reprod. Domest. Anim. 45, 579-584.

Suwannasing, R., Duangjinda, M., Boonkum, W., Taharnklaew, R. and Tuangsithtanon, K. (2018): The identification of novel regions for reproduction trait in Landrace and Large White pigs using a single step genome-wide association study. Asian-Australas. J. Anim. Sci. 31, $1852-1862$.

Taniguchi, M., Nakajima, I., Chikuni, K., Kojima, M., Awata, T. and Mikawa, S. (2014): MicroRNA-33b downregulates the differentiation and development of porcine preadipocytes. Mol. Biol. Rep. 41, 1081-1090.

Taye, M., Lee, W., Jeon, S., Yoon, J., Dessie, T., Hanotte, O., Mwai, O. A., Kemp, S., Cho, S., Oh, S. J., Lee, H. K. and Kim, H. (2017): Exploring evidence of positive selection signatures in cattle breeds selected for different traits. Mamm. Genome 28, 528-541.

Uimari, P., Sironen, A. and Sevón-Aimonen, M-L. (2011): Whole-genome SNP association analysis of reproduction traits in the Finnish Landrace pig breed. Genet. Sel. Evol. 43, 42.

Uzzaman, R., Park, J. E., Lee, K. T., Cho, E. S., Choi, B. H. and Kim, T. H. (2018): A genomewide association study of reproductive traits in a Yorkshire pig population. Livest. Sci. 209, 67-72.

Wang, H., Wu, S., Wu, J., Sun, S., Wu, S. and Bao, W. (2017): Association analysis of the SNP (rs345476947) in the FUT2 gene with the production and reproductive traits in pigs. Genes Genom. 40, 199-206.

Wang, Y., Ding, X., Tan, Z., Xing, K., Yang, T., Pan, Y., Wang, Y., Mi, S., Sun, D. and Wang, C. (2018): Genome-wide association study for reproductive traits in a Large White pig population. Anim. Genet. 49, 127-131.

Whyte, J. J., Meyer, A. E., Spate, L. D., Benne, J. A., Cecil, R., Samuel, M. S., Murphy, C. N., Prather, R. S. and Geisert, R. D. (2018): Inactivation of porcine interleukin-1 $\beta$ results in failure of rapid conceptus elongation. PNAS 115, 307-312.

Wu, P., Wang, K., Yang, Q., Zhou, J., Chen, D., Ma, J., Tang, Q., Jin, L., Xiao, W., Jiang, A., Jiang, Y., Zhu, L., Li, M., Li, X. and Tang, G. (2018a): Identifying SNPs and candidate genes for three litter traits using single-step GWAS across six parities in Landrace and Large White pigs. Physiol. Genomics doi: 10.1152/physiolgenomics.00071.2018.

Wu, P., Yang, Q., Wang, K., Zhou, J., Ma, J., Tang, Q., Jin, L., Xiao, W., Jiang, A., Jiang, Y., Zhu, L., Li, X. and Tang, G. (2018b): Single step genome-wide association studies based on genotyping by sequence data reveals novel loci for the litter traits of domestic pigs. Genomics 110, 171-179.

Xiao-Lei, L., Song-Bai, Y., Rothschild, M. F., Zhi-Wu, Z. and Bin, F. (2012): Genome-wide association study of total number born and number born alive in pigs using both compressed mixed linear model and Bayes model. China Sci. J. 34, 1261-1270. 
Yan, X., Wang, Z., Schmidt, V., Gauert, A., Willnow, T. E., Heinig, M. and Poy, M. N. (2018): Cadm2 regulates body weight and energy homeostasis in mice. Mol. Metab. 8, 180-188.

Yang, C., Zang, W., Ji, Y., Li, T., Yang, Y. and Zheng, X. (2018): Ribosomal protein L6 (RPL6) is recruited to DNA damage sites in a poly (ADP-ribose) polymerase-dependent manner and regulates the DNA damage response. J. Biol. Chem. doi: 10.1074/jbc.RA118.007009.

Zhang, B., Yu, C., Lin, M., Fu, Y., Zhang, L., Meng, M., Xing, S., Li, J., Sun, H., Gao, F. and Zhou, G. (2015): Regulation of skeletal muscle protein synthetic and degradative signaling by alanyl-glutamine in piglets challenged with Escherichia coli lipopolysaccharide. Nutrition 31, 749-756.

Zhang, R., Lei, T., Qi, Y., Lei, P., Chen, Z., Chen, X. and Yang, Z. (2010): Molecular cloning, chromosomal localization and expression pattern of porcine ADP-ribosylation factor (Arf) gene family. Anim. Sci. J. 81, 425-431.

Zhang, X., Liu, X., Zhang, M., Li, T., Muth, A., Thompson, P. R., Coonrod, S. A. and Zhang, X. (2016): Peptidylarginine deiminase 1-catalyzed histone citrullination is essential for early embryo development. Sci. Rep. 6, 38727.

This is an open-access article distributed under the terms of the Creative Commons Attribution 4.0 International License (https://creativecommons.org/licenses/by/4.0/), which permits unrestricted use, distribution, and reproduction in any medium, provided the original author and source are credited, a link to the CC License is provided, and changes - if any - are indicated. (SID_1) 